\title{
Catheter Virtual Lumbar Discectomy (Early and 5 Year Follow-up Results) A New Minimally Invasive Alternative, on an Outpatient Bases
}

\author{
Mohamed Mohi Eldin*
}

Neurosurgery Department, Faculty of Medicine, Cairo University, Egypt

\begin{abstract}
Background: After at least six weeks of conservative management of lumbar disc disease patients, some will require additional treatment. Surgeries available do not offer clear, safe options free of complications in all cases. Moreover, some reported postoperative complications are more difficult to treat than the original illness. I am offering a new modified intervention for such cases.

Objectives: The purpose of this study was to assess the safety and effectiveness of epidural cocktail instillation for lumbar degenerative diseases, confirm its indications, and evaluate the clinical outcomes of patients.
\end{abstract}

Study Design: Patients were prospectively selected to receive catheter virtual discectomy (CVD) in a prospective, randomized, blinded, crossover cohort study.

Setting: The enrollment took place from January 2007 through February 2012 in major tertiary Hospitals in Cairo, including Cairo University Hospitals, Naser Institute Hospital, and Al-Helal Hospital.

Material \& Methods: A total of 100 patients underwent epidural cocktail injections for lumbar degenerative indications by one neurological spine surgeon. The mean follow-up was 48 months.

Outcomes Assessment: After one week, one month and every 3 month thereafter, for the first year, then yearly, the pain was assessed using visual analogue score (VAS). Any decrease in VAS of more than two scales was defined as a significant VAS improvement. Patients were screened for any major or minor complications. The patients were then followed for three up to five years to determine the outcome of treatment. Follow-up images were taken to assess results and determine any injection-related issues.

Results The most prevalent diagnoses were disc bulges, especially in young ages. The mean severity of LBP decreased by $80 \%$ at 3-month follow-up, and $60 \%$ at 1-year follow-up. The results of pain relief were best at early follow-up visits. Forty two patients $(70 \%)$ stated that they would undergo this procedure again. The late 5 year follow up, if not superimposed by an additional new insult, and after exclusion of the 14 patients who did not complete the study, had a stationary clinical course.

Limitations: Fourteen patients did not complete the study, with reasons ranging from loss to follow-up (not returning) to pursuing exclusion criteria items. Eighty six patients were included in the final analysis.

Conclusion Despite the supposed argue, the current study provides evidence that immediate pain relief and increase in function can be provided by the epidural cocktail injections with a very low rate of morbidity. The follow-up images showed, in addition to the clinical improvement, definite structural decrease of the disc bulges in a way as if discectomy was done without any surgical or interventional intervention. That is why the name catheter virtual discectomy (CVD) was introduced.

Keywords: Lumbar disc, epidural drugs, degenerative spine, catheter, cocktail, minimally invasive.

\section{INTRODUCTION}

Low back pain (LBP) is the commonest condition affecting the lumbar spine. Around $80 \%$ of the population experience at least once LBP in their lifetime. The most frequent cause of LBP with sciatica is the disc herniation. The natural history of herniated disc is characterized by disappearance of symptoms in up to $50 \%$ of patients, with

*Address correspondence to this author at the Neurosurgery Department, Faculty of Medicine, Cairo University; Tel: 00201227342964;

Emails: mmohi63@yahoo.com, mmohi63@hotmail.com shrinkage of the disc herniation revealed by MRI within 8 to 9 months after the onset of pain. However, not all patients can wait so long before symptoms improve [1-6]. An initial period of nonoperative management is recommended in such cases. After six weeks of nonoperative management, some patients will have persistent pain and will require additional treatment. Surgeries available do not offer clear, safe options free of complications in all cases. Moreover, some reported postoperative complications are more difficult to treat than the original illness [7-9].

Epidural injections, described by Evans in 1930, have been used in the treatment of disc disease for over 80 years 
and epidural steroids for over 50 years. The procedure has been traditionally performed using a blind technique without fluoroscopic guidance, as described by Barry and Kendal $[10,11]$. Because of many favourable reports, epidurals have been increasingly used. The results obtained from many published studies, suggest a more rational use of that treatment. Several large epidemiologic studies have demonstrated safety and efficacy of this route of therapy in properly selected cases. Safety of epidural route has been well documented and enhanced by avoidance of accidental injection of large doses intravascularly, by continuous monitoring of blood pressure and respiration, and by avoidance of this technique in the presence of anticoagulation. However, epidural route of drug administration has been remarkably stagnant over at least 25 years, with no new drugs developed for epidural administration. Existing agents used include local anesthetics, analgesics, and steroids [10-19].

I am introducing a new modification of that type of therapy, named (catheter virtual discectomy - CVD). Presenting our experience with this new modified procedure in which epidural catheter is used to deliver epidural cocktail of drugs into the desired target (the prolapsed disc and its surroundings), describe the technique of this relatively painless outpatient procedure, and present the complications we encountered. Delivering a unique drug cocktail to deal with the pathology of lumbar disc disease is finally evaluated.

\section{MATERIALS AND METHODS}

\section{Patient Selection}

After Institutional Board approval of the current prospective, randomized, blinded, crossover cohort study, patients were prospectively selected to receive CVD. Patients were initially referred to the outpatient clinic. The diagnosis was confirmed by radiographic studies. The enrollment took place from January 2007 through February 2012 in major tertiary Hospitals in Cairo, including Cairo University Hospitals, Naser Institute Hospital, and Al-Helal Hospital. To qualify for the study, the patients should understand all other treatment options, the results and complications of CVD treatment, and choose the CVD treatment. Each Patient underwent a thorough standard evaluation by a single neurosurgeon. Inclusion criteria include patients with lumbar back pain with or without radicular pain of more than six weeks duration after ruling out infectious or neoplastic causes, and who have had MRIproven intervertebral disc herniation and refractory pain, even after a full dose of medical and physical therapies for more than four weeks duration. None of our patients had previous low back surgery. All had tried full tolerable dose of anti-inflammatory drugs, muscle relaxants, pain killers, and antioedema medications for at least four weeks and physical modalities had failed to show an acceptable response. Exclusion criteria include patient's lack of compliance and/or signs or symptoms denoting any underlying infection, bleeding tendency or malignancy. Patients with previous back surgery were excluded from the study. No patient had a frank instability. Because this series is prospective, with patients under the care of a single neurosurgeon, there were no variations in the selection, technique or follow up criteria.

\section{Patient Population}

A prospective series of 100 patients treated with epidural cocktail injections up to the end of February 2012 was evaluated. All patients had undergone a thorough medical history and physical examination. Patients had undergone MR imaging before the procedure. All available imaging studies were reviewed before injections administered. Patients were informed of potential risks associated with the procedure before intervention. Patients also completed a pain scale survey. After completing the history-taking and careful neurological examination, the patient was categorized into one of the study groups.

Patients were categorized into three clinical groups on the basis of clinical presentation in order to assess the efficacy of treatment.

(A) Acute Group: 38 patients with an acute onset less than 6 months, with no past history of sciatica.

(B) Recurrent Group: 30 patients with a history of recurrent attacks of sciatica, previously improved by conservative treatment.

(C) Chronic Group: 32 patients with a gradual onset of symptoms or a history of more than 6 months and with a poor response to conservative treatment.

\section{The Procedure}

The skin is prepped in a sterile fashion using povidoneiodine (Betadine) followed by an alcohol rinse, after which a fenestrated drape is applied. Local anesthetic (1\% lidocaine) is generally not needed and is only rarely injected subcutaneously, in sensitive patients. A stainless steel 18gauge Tuohy epidural needle is advanced into the epidural space via a posterior approach. The puncture site is typically 2 to $3 \mathrm{~cm}$ caudal to the intended point of entry into the dorsal epidural space (Fig, 1). An interlaminar technique at L3, L4, or L5 was used for most patients. The primary target for injection was at the L4-L5 level, unless any technical problems pushed the operator to the L3-L4 level. A total volume of $10-20 \mathrm{ml}$ was separately injected per injection. The patient was trained to change his or her position every ten minutes after injection for better access of the drug to the diseased area. However, patients are kept in bed, in 45 degree position for at least 2 hours post-injection, and to have absolute bed rest for a week after the last injection.

\section{Insertion Technique}

\section{Interlaminar Lumbar Epidural Catheter Placement}

The catheter is inserted in the affected segment, through the fenestra interlaminaris to the target location. Two different techniques for interlaminar needle insertion were used.

Patients were grouped into 2 different catheter insertion groups, image-guided and blind insertion groups.

1. Image-guided Group: The patient is placed in a prone or lateral position on a fluoroscopy table, or CT table and the target spinal anatomy is assessed with the use of a highresolution images. Assessment of epidural anatomy on MRI facilitates the choice of site for needle placement. The 


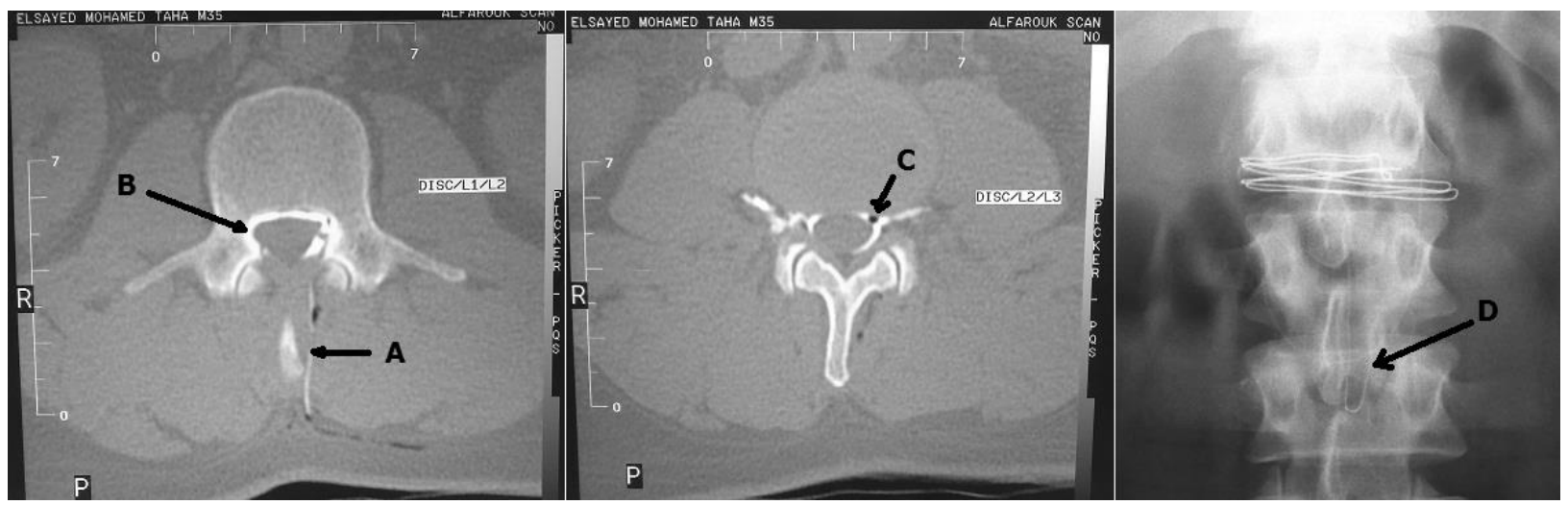

Fig. (1). CT axial cuts at the level of CVD placement showing the epidural catheter (A) entering the epidural space (B) through the interlaminar window. The space is well demonstrated around the dural sac; with the catheter appearing as a signal void (C). The catheter can also be visualized (D) on plain fluoroscopy.

insertion is ideally started one level above, and targeted to the level of greatest disease and pain symptoms, unless there are mitigating circumstances, such as wet or bloody tap, that direct to an alternative insertion site. The intended puncture site may be initially marked on the skin with the C-arm unit in the appropriate orientation. Post-injection films are then obtained to document dispersal of injectate and to demonstrate possible epidural space abnormalities.

2. Blind insertion Group: The distance of lumbar interspinous space to epidural space is normally $2-7 \mathrm{~cm}$ long. The epidural needle is inserted into the skin and advanced while a syringe containing a bubble of air was attached to it. Epidural space was targeted using "loss of resistance" method and confirmed after sensory (numbness) evidence of the proper injection site. This was achieved following free flow of 2-4 $\mathrm{ml}$ of $2 \%$ lidocaine.

In early cases, to document accurate needle placement and to evaluate the epidural space before the instillation of therapeutic substances, in both groups, variable amounts of radiologic contrast material under direct fluoroscopic observation were injected before therapeutic injection, provides improved safety and efficacy. The risk of unintended intrathecal injection and its consequences can be virtually eliminated. Moreover, the practice of soft tissue injections outside the epidural space can be avoided. After checking free flow of saline into the epidural space, the catheter will be fixed and covered with sterile bandage.

Expected epidural blockage may alter the distribution of injected materials and thus explain a patient's response whether unilateral or limited epidural block or a complete block is encountered. In such cases, subsequent injections at a more caudal or cranial location may prove effective to ensure widespread, dispersal of the injectate and to maximize delivery of therapeutic substances to the foramen and epidural space nearest the suspected target disorder. We attempt to perform our CVDs at or as near as is possible to the segmental disease exhibited on imaging studies.

\section{The Injected Cocktail}

For a period of 2-5 days, mostly 3 days, either inpatient or outpatient as preferred by the patient, multiple daily injections of analgesic (xylocaine, fentanyl, \pm magnesium sulfate \& clonidine) and anti-inflammatory (steroids), osmotic (mannitol), ( \pm enzymatic, e.g. Hyalaze) cocktail of drugs will be instilled. These drugs acting together block pain, decrease inflammation, reduce swelling of the affected root and shrink the bulged disc volume. These effects were well documented in previous studies in the literature [20-32]. Following every injection, the patient is kept under supervision for at least one hour to assess initial therapeutic response to the injected drugs, if any. Sedation and cardiac monitoring of patients were not needed in this series. On the last day the catheter will be removed, taking care to see its tip out. During the whole procedure, an antibiotic cover with an effective broad spectrum antibiotic is given, and continued for 2 more days after catheter removal.

\section{Outcome Assessment}

Care and follow-up during and after injection require familiarity with the side effects and complications that might develop in relation to the procedure and/or cocktail components. The procedure-related calls should be suspected before its occurrence. Knowledge of common side effects, complaints, questions, and possible significant complications is an essential part of the procedure. We contact patients between 3 and 7 days after their epidural injection to assess therapeutic response and any unwanted sequelae. If there are any unusual complaints or circumstances, additional followup is then provided. After one week, one month and every 3 month thereafter, for the first year, then yearly, the pain was assessed using visual analogue score (VAS). Any decrease in VAS of more than two scales was defined as a significant VAS improvement. Patients were screened for any major or minor complications. The radiological (MRI) follow up was done at 3 month visit, and at 1 year follow up. The patients were then followed for three up to five years to determine the outcome of treatment.

\section{RESULTS}

Of the 100 patients studied, there were 65 male $(65 \%)$ and 35 female (35\%) patients with ages ranging from 17 to 52 years, with a mean age of 32 years. The duration of pain to epidural injections ranged from 6 weeks to 36 months. Early (1-year) follow up included 100 cases, however 14 patients did not complete the late follow up, with reasons ranging from loss to follow-up (not returning) to pursuing exclusion criteria items. Eighty six patients were included in the final analysis. 


\section{Clinical Outcome}

Success of CVD is defined as a very substantial improvement as regards pain, spinal mobility and straight leg raising, maintained for the period of follow-up. Failure is defined as either no improvement or a temporary or moderate improvement with recurrence of symptoms after continuation of daily activities.

The overall VAS improvement for two weeks and three months after CVD were $65 \%$ and $58 \%$, respectively. In all the three clinical groups, remarkable improvement in onemonth VAS based on low back and radicular pain occurred in $75(75 \%)$ patients. VAS values for the acute, recurrent and chronic groups were different at two weeks and three months post-injection periods. Better results were obtained from patients from the acute and recurrent groups after one month. Even though, slightly better results were obtained in the twoweek follow-up in the acute group. On the other hand, differences in VAS improvement in the second week, one month, and three month follow-up was less in the chronic group. In the chronic group, 6 cases complained of pain aggravation after CVD, 13 cases had improvements of less than two scores [mild to moderate] and the remaining 13 cases felt neither remarkable improvement nor worsening in pain perception during the follow-up period. These chronic cases not responding to CVD treatment was subjected to surgical intervention later on.

Patients who showed improvement followed by relapse $(15 \%)$ had a second epidural after 3 months and of these, $(10 \%)$ benefitted from the second injection and were classed as successes. It can be seen that there was a significant improvement in the success rate in patients having their epidural within 6 months of the onset of symptoms and those in the "acute" category.

The presence of degenerative changes on plain X-ray of the lumbar spine, mostly in the chronic group, did affect the results of CVD treatment. The more the mechanical bony affection, the less favourable is the result. Variations in the injection technique, blind or fluoroscopically-guided, did not affect the results of the treatment but variations in the protocol of the injection (number of injections) appeared to affect the results in acute cases. The 5-day results was better than the 3-day results clinically.

The present series showed $80 \%$ success rate in "acute group", 60\% in "recurrent group" and 40\% in "chronic group" cases; the acute and recurrent patients having CVDs within 6 months of the onset of symptoms, the chronic patients, having had symptoms for longer than 6 months when given their CVDs.

As expected, most patients reported that the treatment was a good choice and could be repeated if needed. Patients for whom CVD had failed and who then underwent discectomy did as well as the patients in the original study.

The late 5 year follow up, if not superimposed by an additional new insult, and after exclusion of the 14 patients who did not complete the study, had a stationary clinical course.

\section{Access Failures}

In two patients, a wet spinal tap precluded access to the epidural space. Another higher catheter insertion was done, without any subsequent drug instillation for 24 hours. These 2 patients were treated routinely thereafter using our standard protocol, which most likely would have circumvented this obstacle. In 9 cases, catheter obstruction necessitates another catheter insertion. One of them was obstructed immediately after insertion. That is why, routine check of free flow of saline along the catheter before injection is mandatory. Accidental catheter extrusion occurred in another 3 cases, in which another catheter has to be inserted. Failure of access the interlaminar gap was not recorded.

\section{Complications}

Reported complications occurred early in our experience. There were no major complications including epidural haematoma or abscess formation. There were no local or epidural infections in this series. None of these patients had other delayed complications. The overall incidence of minor complications in all groups were transient hypotension and vomiting in two cases $(3.3 \%)$, flushing in six cases $(10 \%)$, cerebrospinal fluid (CSF) hypotension secondary to dural puncture in one case $(1.7 \%$ ) (five cases had headache without any CSF leak), and transient sensation of chest compression in five cases $(8.3 \%)$.

Significant transient hypotensive episode reported in one patient, recovered few minutes later. The other patient had vomiting with a severe vasovagal response after injection due to rapid injection, in the sitting position. She was observed for 3 hours in the emergency department, with no residual complications. Her back pain was nevertheless dramatically relieved by the procedure. That is why, slow injection technique is mandatory, in the lying down posture, to avoid such a complication.

\section{Radiological Outcome}

Reviewing the radiological follow up images of all the study cases at different follow up visits, clinical improvements was associated with definite radiological improvement in the form of definite volume decrease of the bulged, or prolapsed disc material, as shown clearly in Figs. (2 to 10). On the other hand, the absence of clinical improvement was associated with mild or no radiological changes. Cases with recurrence of symptoms had either no radiological changes or moderate volume changes, not enough to result in definite clinical change.

Volume reduction is especially effective in high intensity zones (HIZs), both clinically \& radiologically. Volume change is reflected on the disc bulge, cross-diameter of the spinal canal \& on the posterior longitudinal ligament, with reduction of the bulge, increase in cross-diameter of canal \& posterior longitudinal ligament relaxation accompanied with resulting clinical improvement.

\section{DISCUSSION}

Lumbar discogenic pain (LDP) could be related to mechanical and inflammatory causes. The inflammatory causes include immune response to the protruded disc material in the form of cell-mediated, biohumoral factors and inflammatory enhancers. Thus, logically speaking, antiinflammatory medications are the corner stones in the treatment of that type of pain. 

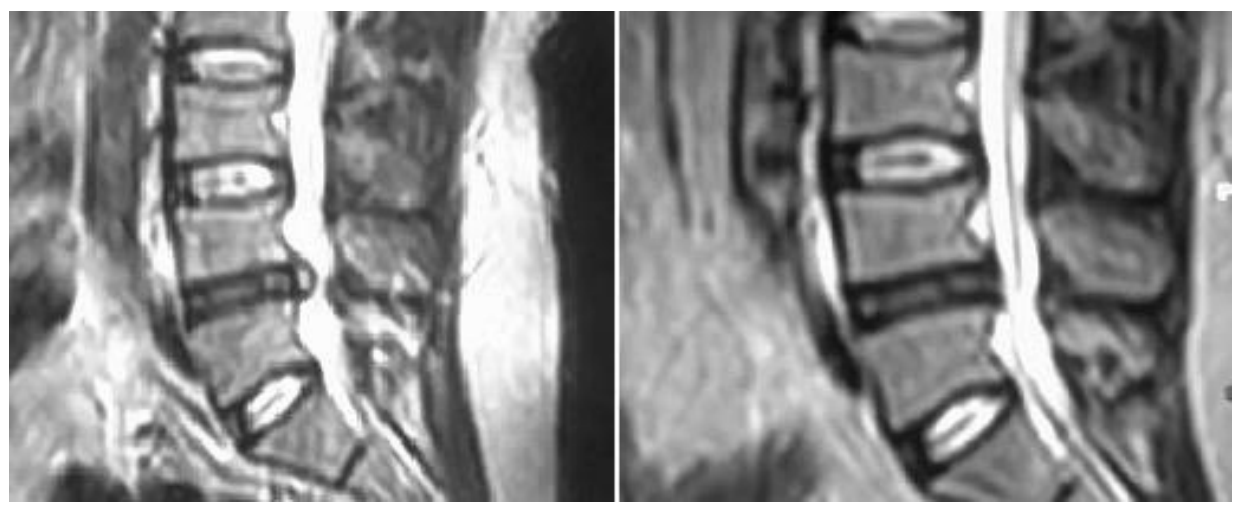

Fig. (2). A pre-injection MRI showing L4,5 disc bulge, in a 35 years old male. Notice the post-injection difference in MRI image, with gradual decrease in size at I month post-injection and as if the bulge was cut by a knife, 3 months later.
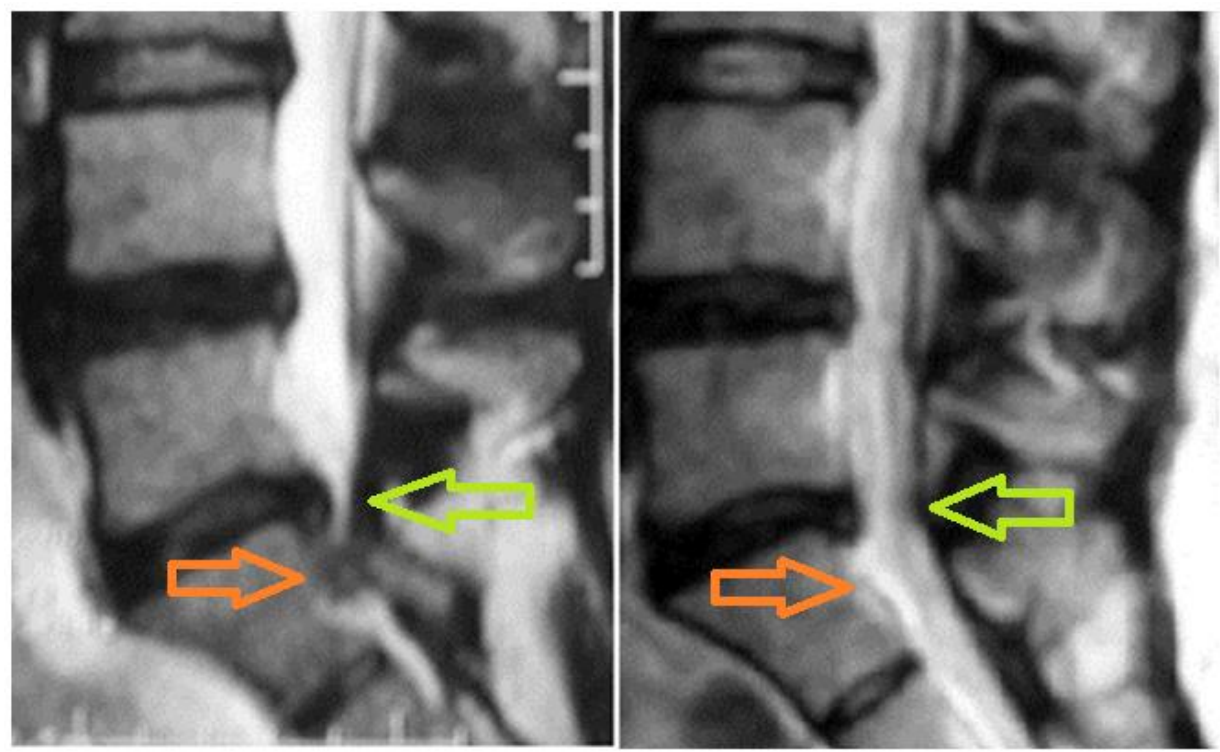

Fig. (3). A pre-injection MRI showing L5-S1 disc protrusion. Notice the post-injection difference in MRI image, the protrusion volume grossly decreased.
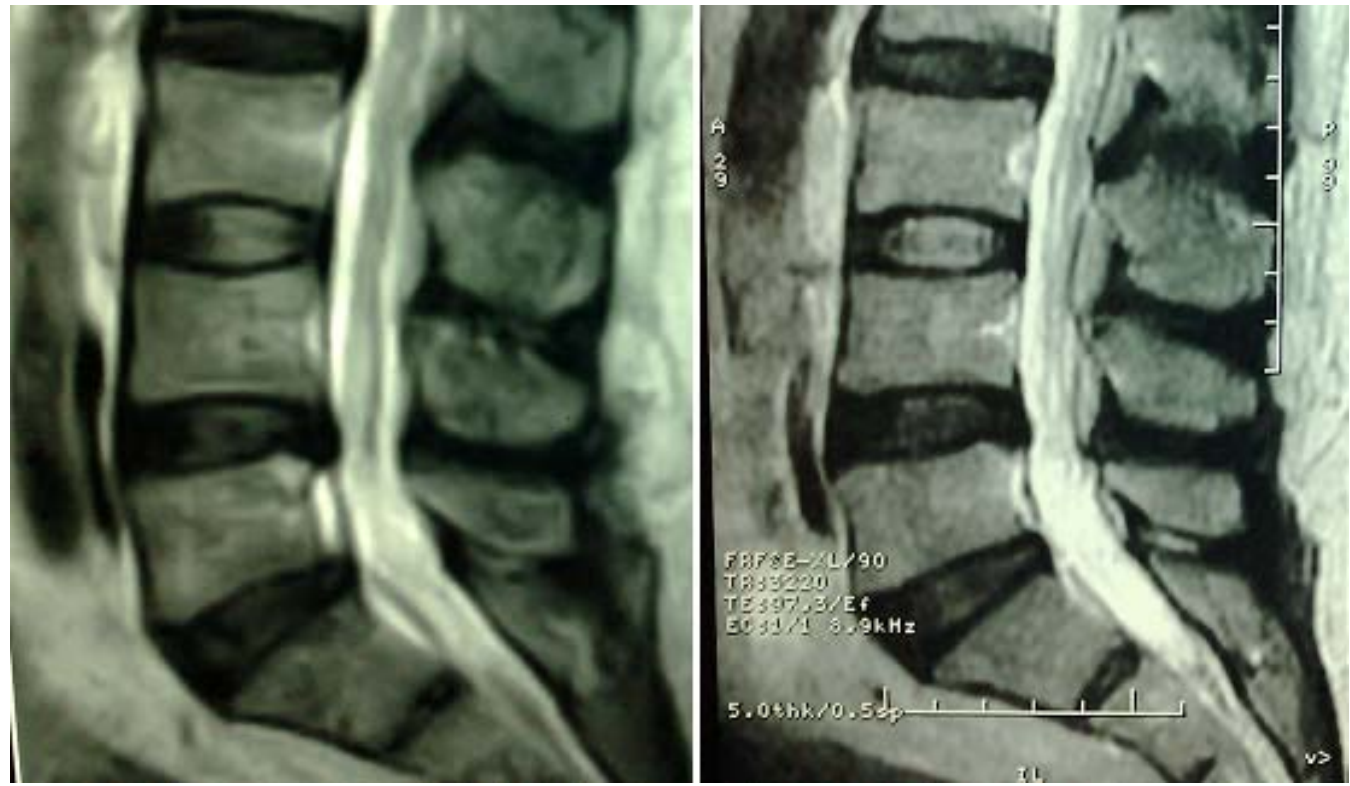

Fig. (4). Saggital MRI images showing multilevel disc lesions, which are shown to change in size in relation to post-injection images. 

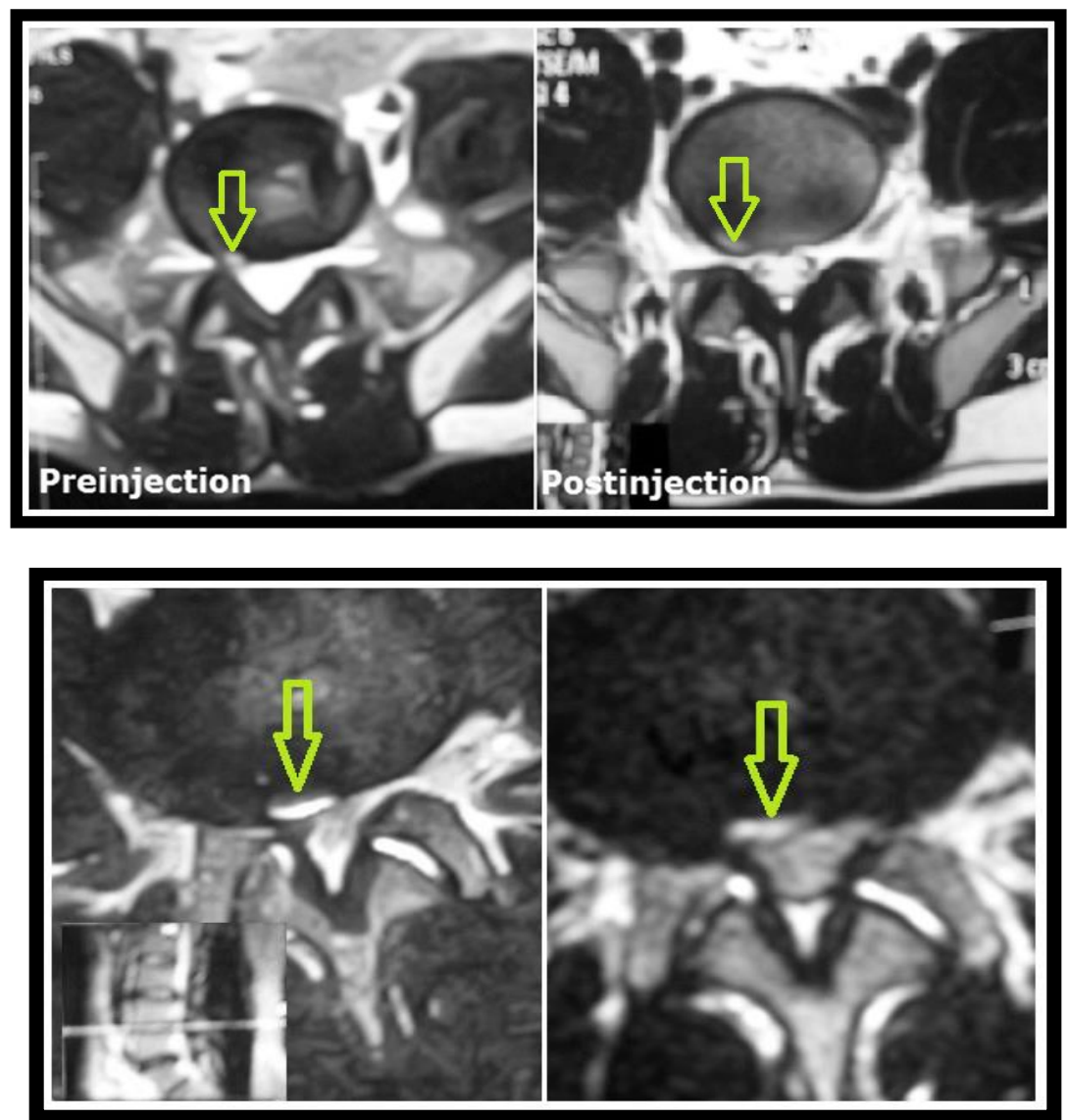

Fig. (5). Axial MRI images of 2 different cases showing unilateral foraminal stenosis which apparently decreased post-injection, accompanied with marked clinical improvement. It is especially effective in high intensity zones (HIZs), both clinically \& radiologically.
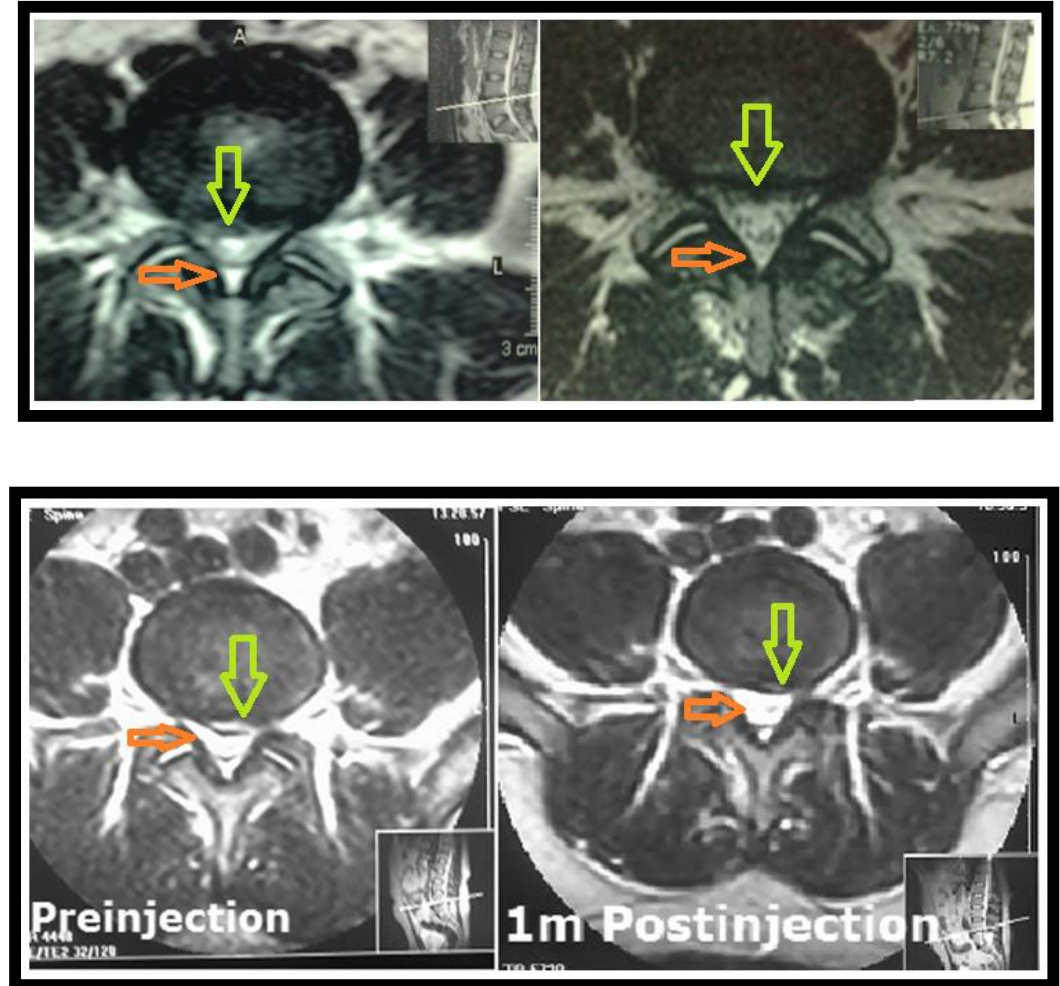

Fig. (6). Axial MRI images of 2 different cases, showing volume change reflected on the disc bulge \& cross-diameter of the spinal canal, accompanied with marked clinical improvement. 

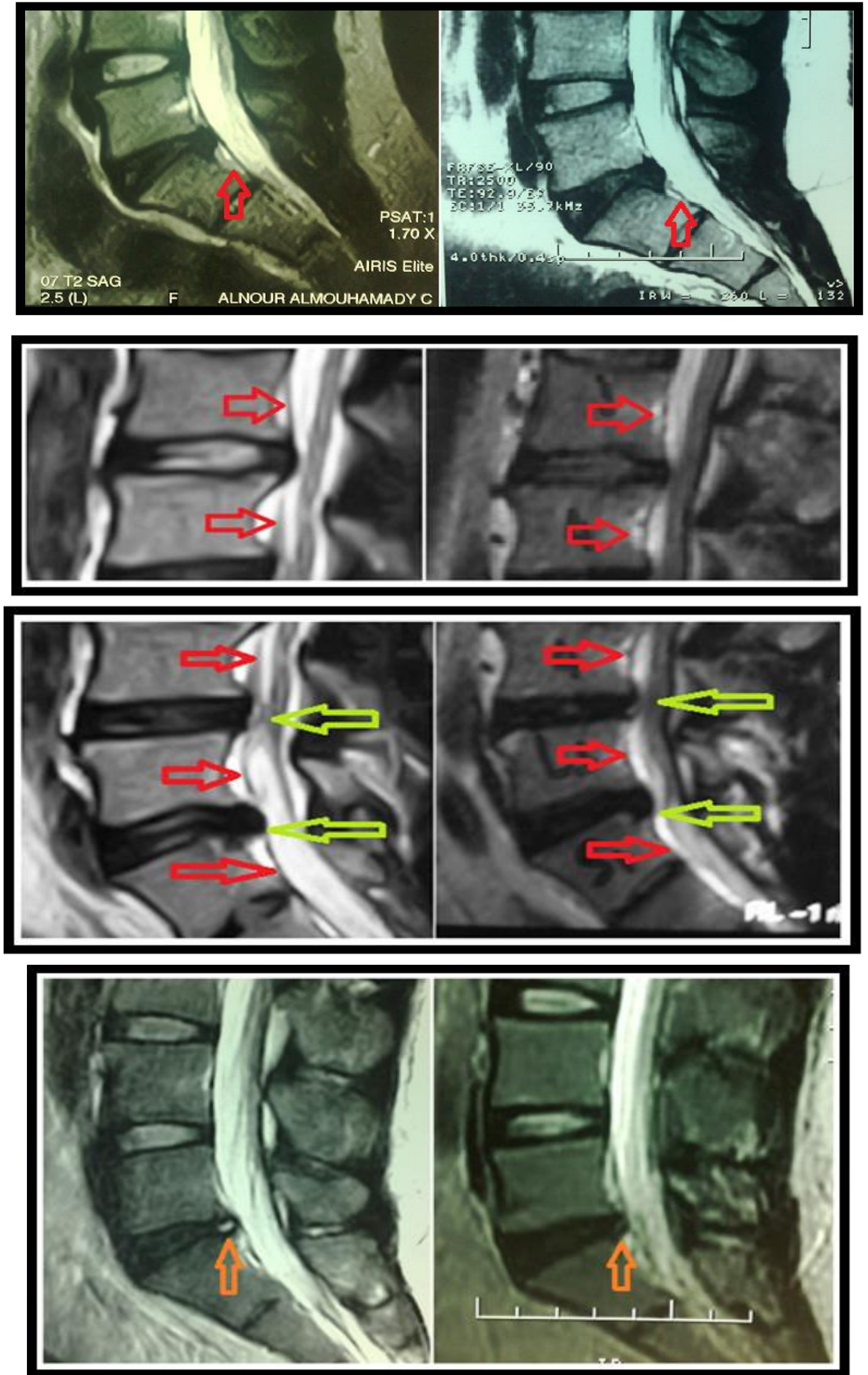

Fig. (7). Saggital MRI images of 4 different cases, showing volume change reflected on the disc bulge \& on the posterior longitudinal ligament, with posterior longitudinal ligament relaxation accompanied with marked clinical improvement. 


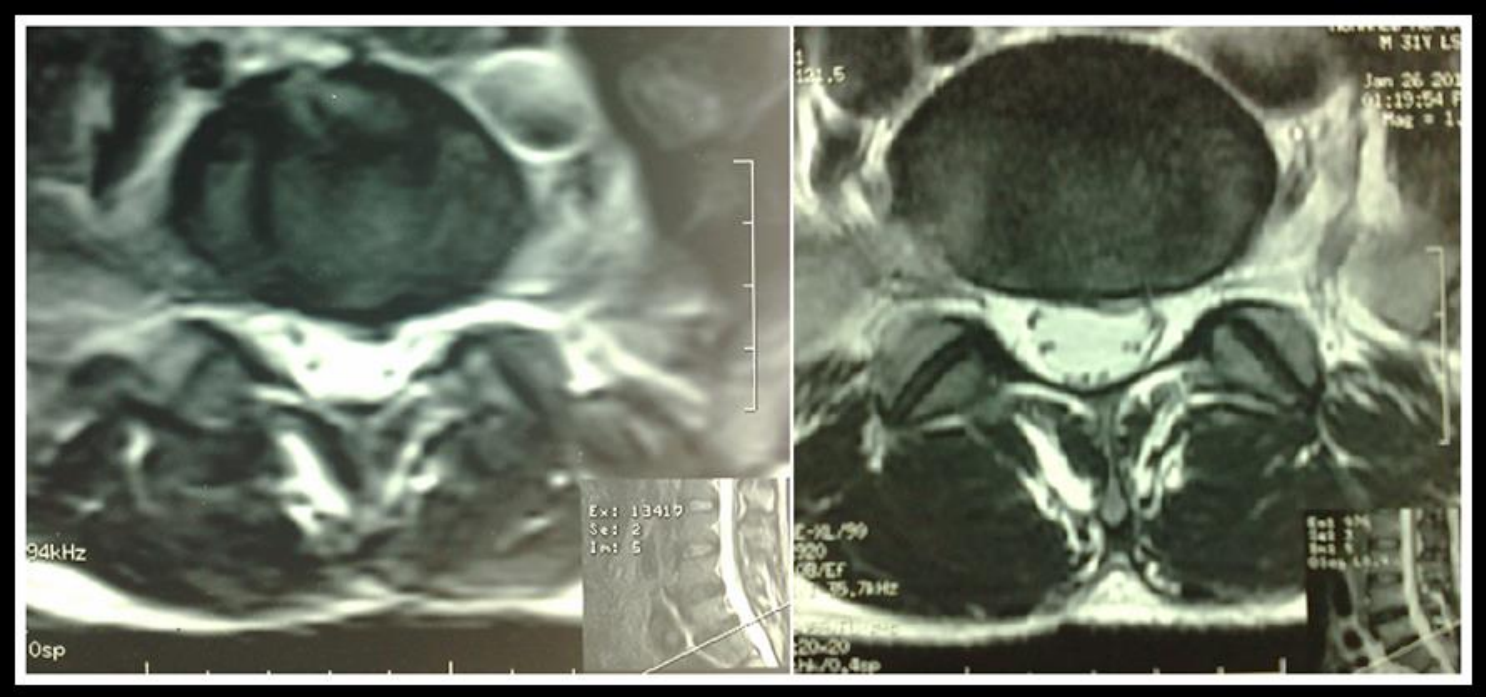

Fig. (8). Axial MRI images, showing volume change reflected on the disc bulge \& cross-diameter of the spinal canal, accompanied with marked clinical improvement. A small change in volume produces large change in pressure and marked clinical improvements,

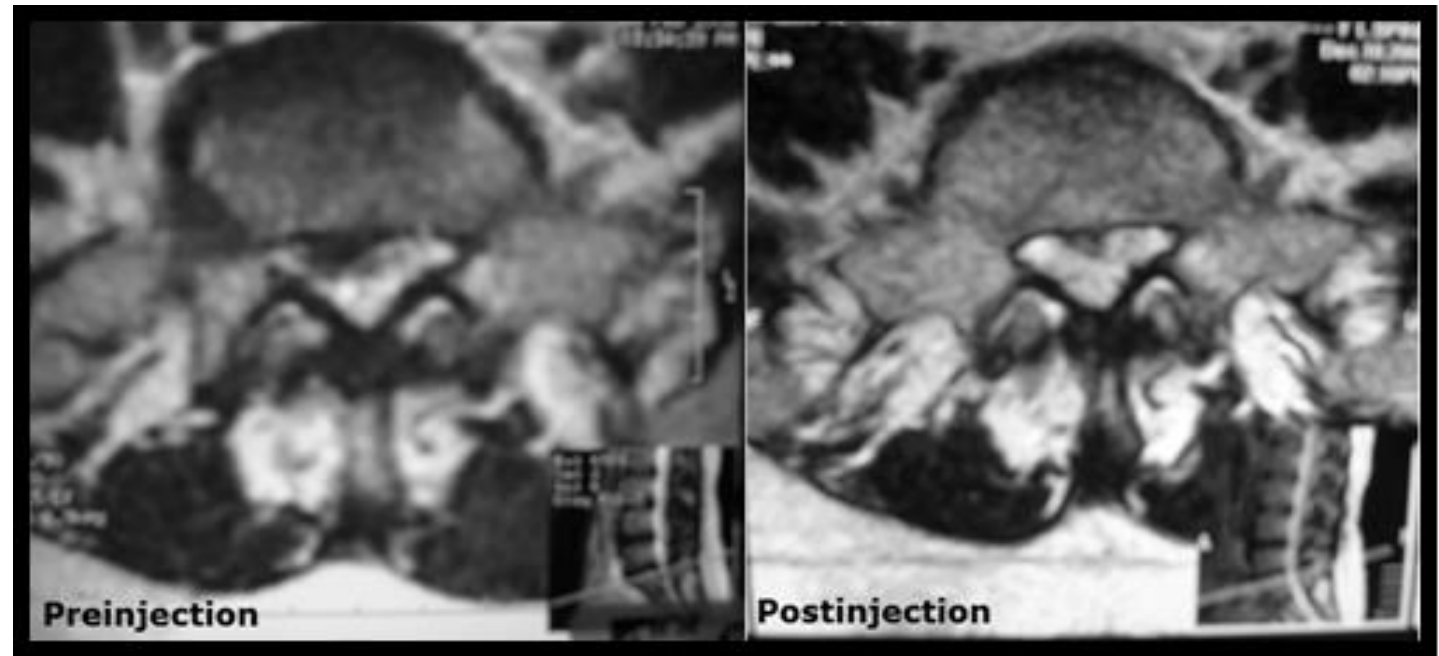

Fig. (9). Axial MRI images showing postero-lateral L5-S1 disc protrusion which apparently decreased 6m post-injection, accompanied with partial clinical improvement. A moderate change in volume may still produce moderate clinical improvements, according to the type and shape of the bulge.

Regarding the mechanical causes of LDP, they are both direct (compression of the nerve roots, deformation of the ligaments and annulus, and stimulation of the nociceptors of Luschka's nerve of the posterior root of the spinal nerve, mechanical surface contact), and indirect (ischaemia due to arterial compression, and venous stasis). Muscle spasm also play a role. To counteract these mechanical effects, the unique microstructure of the intervertebral disc (IVD) was studied. The IVD has a heterogeneous structure made of two different regions, namely the annulus fibrosus (AF), and the nucleus pulposus (NP). The nucleus appears macroscopically cloudy and jelly-like and is composed mostly of water, collagen and proteoglycans. The annulus is similar in composition to the nucleus, with less water and a greater amount of collagen. The annulus has a laminar structure that is regular on the outer most regions of the IVD with thick lamellae, but begins to lose some laminar structure closer to the nucleus. The IVD is populated by chondrocyte-like or fibrochondrocyte-like cells of mesenchymal origin in all zones as well as larger, highly vacuolated notochordal cells present only in the NP. These cells are responsible for the synthesis of the IVD matrix during development and maintenance of the extracellular matrix throughout life. Previous studies have shown that changes in the osmotic environment alter the biosynthetic response of IVD cells, potentially serving as a regulator of disk metabolism in both health and disease $[1,2,5,33-38]$.

The idea of the present study is to have a new drugs mixture by which we can alter, virtually, without any invasive or even minimally invasive structural intervention, the lumbar disc disease scenario, and manage the presenting clinical and radiological pictures. We took into consideration important findings of previous studies, namely, successful epidural steroid injection (ESI) alone, and volume changes in response to osmotic stresses. Understanding where collagen or water is concentrated in the intervertebral disc could point to how the disc works to cushion loads, flex, and move and respond to stress. The hydrostatic pressure of water concentrated in the nucleus \& the laminar fabric of the collagen fibres in the annulus may respond to stress. Also, water may diffuse from one area into another. 


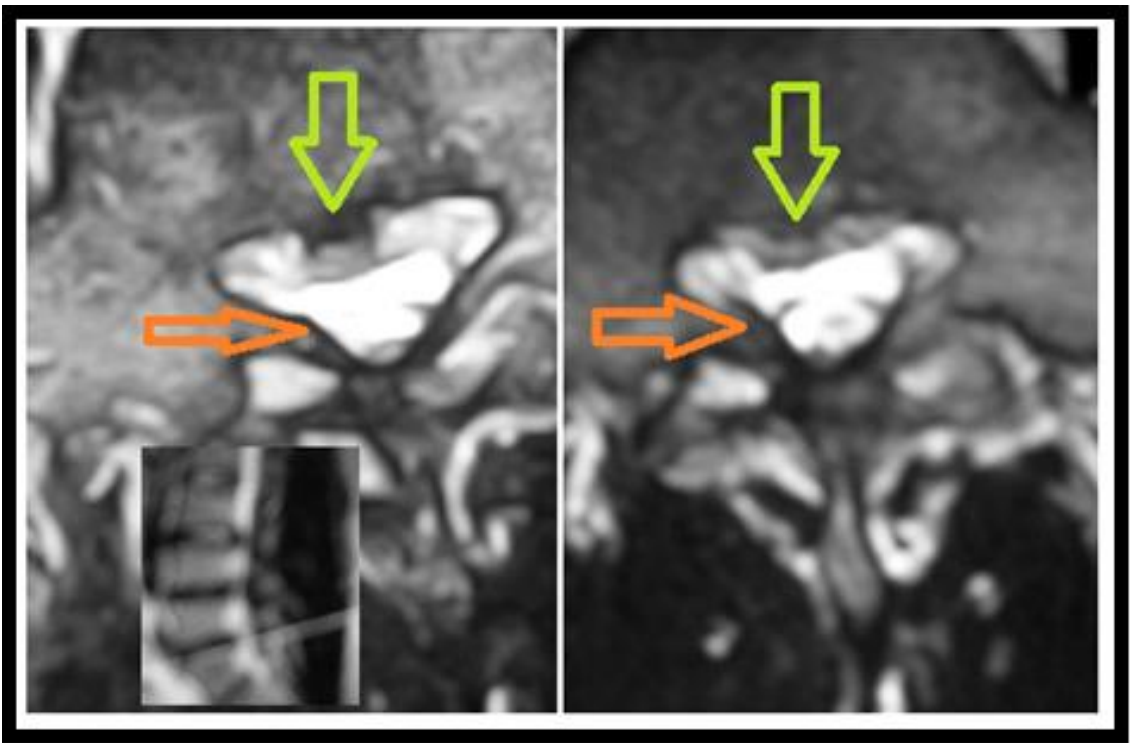

Fig. (10). Axial MRI images showing postero-bilateral L5-S1 disc protrusion which apparently decreased post-injection, accompanied with no clinical improvement. A change in volume may be moderate, but clinically ineffective specially in mixed disc types.

Regarding ESI, some studies reported lumbar disc herniation regression after successful ESI alone. Patients who were successfully treated conservatively and whose pain decreased significantly within the first six weeks were found to have a larger number of resorbed extruded and sequestered disc herniations on follow-up magnetic resonance imaging (MRI) [39-41]. Carette et al showed a slightly better improvement in leg pain over six weeks in a randomised controlled trial of ESI in patients with sciatica due to herniated discs [42].

Regarding disc volume changes, normally, the IVD under dynamic compressive loads shows diurnal variations in disc height and water content. The biophysical mechanisms involved are not fully understood, but are believed to involve changes in the interstitial osmolality or $\mathrm{pH}$ secondary to exudation of interstitial water. As the cell membrane is relatively permeable to water, increasing the extracellular osmolality leads to a decrease in cell volume. The mechanism by which IVD cells are able to transduce the applied osmotic stress is unclear. The response is triggered not only by the presence of an osmotic gradient, but rather by some downstream cellular response to the osmotic stress (cellular volume change, membrane stretch, and membrane depolarization). Within the IVD, zonal variations in the cellular volumetric response to hyperosmotic stress were also observed. The volume adaptation characteristics of NP differed markedly from those of AF [24, 43-53].

Given these findings of volume changes in response to osmotic changes, our idea suggests that the addition of hyperosmotic media to the antioedema and antiinflammatory media have a good chance of decreasing the volume of the prolapsed disc material. This hypothesis is supported by our findings of definite clinical and radiological improvement in properly selected cases. Reducing intervertebral disc size by chemical aspiration of water of the HIZ or partially shrinking the herniation by drying reduces the pressure on the torn annulus and creates a space for bulge regression whenever the tension of the annular fibres regain capacity to contain the disc. The proposed suggestion is that a small change in volume produces large change in pressure, and later allows healing of the annular cracks [24, 43-53].

Widely differing results have been published by various authors using epidural injections, and various combinations of saline, local anaesthetic and steroid injections have been used and the results differ significantly even in series using the same medication. Revising these series, it was obvious that the precise selection of the cases is of importance in determining the results and indeed a look at published work shows that very little attempt has been made to relate the results of treatment to the precise cause of the symptoms and this almost certainly accounts for the differences in the results [54-66].

It is reasonable to assume that the earlier a CVD is given the more effective it will be, and that the more chronic the case is, the more the failure rate will be. Chronicity may indicate a tight mechanical compression, a nerve root infiltrated with chronic inflammatory cells, ischaemic root, or neuropathic type of pain that may need different treatment methodologies. This concept is borne out by the observations from the present series, i.e., a $60-80 \%$ success in all patients having CVDs within 6 months of the onset of symptoms, with only a $40 \%$ success in "chronic" patients, having had symptoms for longer than 6 months when given their CVD.

As most minimally invasive procedures, CVD needs only a short hospital stay, or even nonhospital, outpatient protocol. It also eliminates the risks of post-operative scarring linked to surgery which is responsible for recurrence of pain in many cases. CVD can also be repeated in the same patient leaving the anatomical corridors intact and normal if they should fail. The success rates reported in our study vary from 50 to $80 \%$ of excellent or good results, according to the selection criteria.

White and co-workers found that inaccurate needle placement occurred in $25 \%$ to $30 \%$ of blinded techniques, even in skilled and experienced hands [67]. Based on the high rate of erroneous needle placement described in the 
literature and the potentially devastating effects of intrathecal drug injection, we used to perform epidurography in conjunction with CVD in image-guided group of patients unless there is either a history or reasonable suspicion of allergy to iodinated contrast agents. It is a safe outpatient procedure that can assure correct needle placement and demonstrate anatomic features [68,69]. The use of $5 \mathrm{~mL}$ of water-soluble contrast material in order to adequately identify the epidural space is usually enough. However, in the present study, no significant difference was noted between the two groups in expert hands. Only early in the study the difference was significant. In the literature, the argument between the two insertion techniques holds true and this is especially important in our multi-session CVD technique. However, after doing a lot of these techniques and after evaluation of both interventionists and aneasthetists, it would be fair enough to say that if one masters the technique, either blind or image-guided, erroneous needle placement would be minimized. In skilled hands, our procedure ensures delivery of the therapeutic materials into the epidural space and prevents complications due to intrathecal or intravascular injections [70-74].

It is our practice to perform at least three consecutive epidural instillations. If there is any doubt, injectate delivery was shown to be accurate with epidurography. Another CVD can be repeated for nonresponders, if indicated. We have reviewed the efficacy of CVD in our daily practice and have confirmed a high rate of success of a non-invasive procedure on outpatient bases with low morbidity. Moreover, using CVD is justified by the patients. Before CVD, discussing the technique with the patient make them keen to try. After CVD, most of our patients have commented on the relatively painless nature of the procedure as compared with any other intervention. This is important as no patient was sedated before the procedure. So, cardiac monitoring is not required for CVD when performed under these circumstances. Thus, CVD is extremely safe and causes minimal patient discomfort, making the procedure ideally suited to outpatient settings. Performing CVD in an awake and fully alert patient virtually eliminates the potential for serious complications when done by skilled, experienced spine surgeon.

\section{CONCLUSION}

Despite the supposed argue, this series confirms the value of Catheter virtual discectomy (CVD) in the treatment of lumbar disc protrusions. The current study provides evidence that immediate pain relief and increase in function can be provided by CVD with a very low rate of morbidity. It is a safe \& effective treatment for symptomatic lumbar disc herniations in nearly one-half, if not more, of the patients treated. The follow-up images showed, in addition to the clinical improvement, definite structural decrease of the disc. Failures are largely due to continued mechanical pressure on the nerve root, especially with hard disc protrusions, in chronic cases. The current study adds further credence to our belief that most patients with lumbar radicular pain without neurologic deficits should first be offered CVD injection trial, especially in young patients.

\section{ACKNOWLEDGEMENT OF FUNDING}

There is no financial disclosure what so ever.

\section{ANY CONFLICTS OF INTEREST}

There were no conflicts of interest, and all the study processings are strictly adherent to the known ethical rules.

\section{REFERENCES}

[1] Bressler HB, Keyes WJ, Rochon PA, Badley E. The prevalence of low back pain in the elderly. A systemic review of the literature. Spine 1999; 24: 1813-9.

[2] Cassidy JD, Cote P, Carroll LJ, Kristman V. Incidence and course of low back pain episodes in the general population. Spine 2005; 30: 2817-23.

[3] Cecchi F, Debolini P, Lova RM, et al. Epidemiology of back pain in a representative cohort of Italian persons 65 years of age and older: the InCHIANTI study. Spine 2006; 31: 1149-55.

[4] Mortimer M, Pernold G, Wiktorin C. Low back pain in a general population. Natural course and influence of physical exercise--a 5year follow-up of the Musculoskeletal Intervention CenterNorrtalje Study. Spine 2006; 31: 3045- 51.

[5] Verhaak PF, Kerssens JJ, Dekker J, Sorbi MJ, Bensing JM. Prevalence of chronic benign pain disorder among adults: a review of the literature. Pain 1998; 77: 31-9.

[6] Walker BF, Muller R, Grant WD. Low back pain in Australian adults: prevalence and associated disability. J Manip Physiol Ther 2004; $27: 238-44$.

[7] Loupasis GA, Stamos K, Katonis PG, Sapkas G, Korres DS, Hartofilakidis G. Seven- to 20-year outcome of lumbar discectomy. Spine 1999; 24: 2313-7.

[8] Pappas CT, Harrington T, Sonntag VK. Outcome analysis in 654 surgically treated lumbar disc herniations. Neurosurgery 1992; 30 : 862-6.

[9] Yorimitsu E, Chiba K, Toyama Y, Hirabayashi K. Long-term outcomes of standard discectomy for lumbar disc herniation: a follow-up study of more than 10 years. Spine 2001; 26: 652-7.

[10] Parr AT, Diwan S, Abdi SA. Lumbar interlaminar epidural injections in managing chronic low back and lower extremity pain: a systematic review. Pain Physician 2009; 12: 163-88.

[11] Manchikanti L, Boswell MV, Datta S, et al. Comprehensive Review of Therapeutic Interventions in Managing Chronic Spinal Pain. Pain Physician 2009; 12: E123-98.

[12] Abdi S, Lucas LF, Datta S. Role of epidural steroids in the management of chronic spinal pain: a systematic review of effectiveness and complications. Pain Physician 2005; 8: 127-43.

[13] Boswell M, Hansen H, Trescot A, Hirsch J. Epidural steroids in the management of chronic spinal pain and radiculopathy. Pain Physician 2003; 6: 319-34.

[14] Boswell MV, Shah RV, Everett CR, et al. Interventional techniques in the management of chronic spinal pain: evidencebased practice guidelines. Pain Physician 2005; 8: 1-47.

[15] Manchikanti L, Staats PS, Singh V, et al. Evidence-based practice guidelines for interventional techniques in the management of chronic spinal pain. Pain Physician 2003; 6: 3-80.

[16] Manchikanti L, Singh V, Kloth DS, et al. Interventional techniques in the management of chronic pain: part 2.0. Pain Physician 2001; 4: 24-96.

[17] Manchikanti L, Singh V, Bakhit CE, Fellows B. Interventional techniques in the management of chronic pain: part 1.0. Pain Physician 2000; 3: 7-42.

[18] Bogduk N, Christophidis N, Cherry D. Epidural use of steroids in the management of back pain. Report of working party on epidural use of steroids in the management of back pain. National Health and Medical Research Council. Canberra, Commonwealth of Australia, 1994; pp. 1-76.

[19] Manchikanti L, Pakanati RR, Pampati V. Comparison of three routes of epidural steroid injections in low back pain. Pain Digest 1999; 9: 277-85.

[20] Chatani K, Kusaka Y, Mifune T, Nishikawa H. Topographical differences of $1 \mathrm{H}-\mathrm{nmr}$ relaxation times (T1, T2) in the normal intervertebral disc and its relationship to water content. Spine 1993, 18: $2271-5$.

[21] Chiu EJ, Newitt DC, Segal MR, Hu SS, Lotz JC, Majumdar S. Magnetic resonance imaging measurement of relaxation and water diffusion in the human lumbar intervertebral disc under compression in vitro. Spine 2001; 26: E437-4. 
[22] Eyre DR. Biochemistry of the intervertebral disc. Int Rev Connect Tissue Res 1979; 8: 227-70.

[23] Eyre DR, Muir H, Types I and II collagen in intervertebral disc. Biochem J 1976; 157: 267-70.

[24] Alexopoulos L, Erickson G, Guilak F. A method for quantifying cell size from differential interference contract (DIC) images: validation and application to osmotically stressed chondrocytes. J Microsc 2002; 205: 125-35.

[25] Bibby KJ, McCulloch CA. Regulation of cell volume and [Ca2_]i in attached human fibroblasts responding to anisosmotic buffers. Am J Physiol Cell Physiol 1994; 266: C1639-49.

[26] Bush PG, Hall AC. The osmotic sensitivity of isolated and in situ bovine articular chondrocytes. J Orthop Res 2001; 19: 768-78.

[27] Cantiello HF. Role of actin filament organization in cell volume and ion channel regulation. J Exp Zool 1997; 279: 425-35.

[28] Dascalu A, Korenstein R, Oron Y, Nevo Z. A hyperosmotic stimulus regulates intracellular $\mathrm{pH}$, calcium, and $\mathrm{S}-100$ protein levels in avian chondrocytes. Biochem Biophys Res Commun 1996; 227: 368-73.

[29] Erickson GR, Alexopoulos LG, Guilak F. Hyperosmotic stress induces volume change and calcium transients in chondrocytes by transmembrane, phospholipid, and G-protein pathways. J Biomech 2001; 34: 1527-35.

[30] Errington RJ, Puustjarvi K, White IRF, Roberts S, Urban JPG. Characterization of cytoplasm-filled processes in cells of the intervertebral disk. J Anat 1998; 192: 369-78.

[31] Guilak F, Erickson GR, Ting-Beall HP. The effects of osmotic stress on the viscoelastic and physical properties of articular chondrocytes. Biophys J 2002; 82: 720-7.

[32] Verkman AS, van Hoek AN, Ma T, et al. Water transport across mammalian cell membranes. Am J Physiol Cell Physiol 1996; 270: C12-30.

[33] Buckwalter JA. Aging and degeneration of the human intervertebral disk. Spine 1995; 20: 1307-14.

[34] Guilak F, Ting-Beall HP, Baer AE, Trickey WR, Erickson GR, Setton LA. Viscoelastic properties of intervertebral disk cells. Identification of two biomechanically distinct cell populations. Spine 1999; 24: 2475-83.

[35] Oegema TR. Biochemistry of the intervertebral disk. Clin Sports Med 1993; 12: 419-39.

[36] Trout JJ, Buckwalter JA, Moore KC, Landas SK. Ultrastructure of the human intervertebral disk. I. Changes in notochordal cells with age. Tissue Cell 1982; 14: 359-69.

[37] Urban JP, Ishihara H, Mouat MJ. Differential metabolic responses of the nucleus and outer annulus to changes in extracellular physical factors. Trans Orthop Res Soc 1994; 19: 134.

[38] Wang JY, Baer AE, Kraus VB, Setton LA. Intervertebral disk cells exhibit differences in gene expression in alginate and monolayer culture. Spine 2001; 26: 1747-52.

[39] Cuckler JM, Bernini PA, Wiesel SW, Booth RE Jr, Rothman RH, Pickens GT. The use of epidural steroid in the treatment of radicular pain. J Bone Joint Surg 1985; 67: 63-6.

[40] Dilke TF, Burry HC, Grahame R. Extradural corticosteroid injection in the management of lumbar nerve root compression. $\mathrm{Br}$ Med J 1973; 2: 635-7.

[41] Klenerman L, Greenwood R, Davenport HT, White DC, Peskett S. Lumbar epidural injections in the treatment of sciatica. $\mathrm{Br} \mathrm{J}$ Rheumatol 1984; 23: 35-8.

[42] Carette S, Leclaire R, Marcoux S, et al. Epidural corticosteroid injections for sciatica due to herniated nucleus pulposus. N Engl J Med 1997; 336: 1634-40.

[43] Antoniou J, Steffen T, Nelson F, et al. The human lumbar intervertebral disk: evidence for changes in the biosynthesis and denaturation of the extracellular matrix with growth, maturation, aging, and degeneration. J Clin Invest 1996; 98: 996-1003.

[44] Baer AE, Wang JY, Kraus VB, Setton LA. Collagen gene expression and mechanical properties of intervertebral disk cellalginate cultures. J Orthop Res 2001; 19: 2-10.

[45] Colliou OK, Chin JR, Liebenberg EC, Lotz JC. Matrix disorganization, apoptosis and gene expression in the intervertebral disk are modulated by compressive loading: a mouse model for disk degeneration. Trans Orthop Res Soc 1998; 23: 189.

[46] Dascalu A, Korenstein R, Oron Y, Nevo Z. A hyperosmotic stimulus regulates intracellular $\mathrm{pH}$, calcium, and $\mathrm{S}-100$ protein levels in avian chondrocytes. Biochem Biophys Res Commun 1996; 227: 368-33.
[47] Ishihara H, Warensjo K, Roberts S, Urban JP. Proteoglycan synthesis in the intervertebral disk nucleus: the role of extracellular osmolality. Am J Physiol Cell Physiol 1997; 272: C1499-506.

[48] Malko JA, Hutton WC, Fajman WA. An in vivo magnetic resonance imaging study of changes in the volume (and fluid content) of the lumbar intervertebral disks during a simulated diurnal load cycle. Spine 1999; 24: 1015-22.

[49] McMillan DW, Garbutt G, Adams MA. Effect of sustained loading on the water content of intervertebral disks: implications for disk metabolism. Ann Rheum Dis 1996; 55: 880-7.

[50] Ohshima H, Tsuji H, Hirano N, Ishihara H, Katoh Y, Yamada H. Water diffusion pathway, swelling pressure, and biomechanical properties of the intervertebral disk during compression load. Spine 1989; 14: 1234-44

[51] Ohshima H, Urban JP, Bergel DH. Effect of static load on matrix synthesis rates in the intervertebral disk measured in vitro by a new perfusion technique. J Orthop Res 1995; 13: 22-9.

[52] Paajanen H, Lehto I, Alanen A, Erkintalo M, Komu M. Diurnal fluid changes of lumbar disks measured indirectly by magnetic resonance imaging. J Orthop Res 1994; 12: 509-14.

[53] Toribatake Y, Hutton WC, Elmer WA, Whitesides TE, Tomita K. An in vivo study of the effect of applied compressive force on intervertebral disk metabolism. Trans Orthop Res Soc 1997; 22: 145.

[54] Byrod G, Otani K, Brisby H, Rydevik B, Olmarker K. Methylprednisolone reduces the early vascular permeability increase in spinal nerve roots induced by epidural nucleus pulposus application. J Orthop Res 2000; 18: 983-7.

[55] Flower RJ, Blackwell GJ. Anti-inflammatory steroid induced biosynthesis of aphospholipase A2 inhibitor which prevents prostaglandin generation. Nature 1979; 278: 456-9.

[56] Lundin A, Magnuson A, Axelsson K, Nilsson O, Samuelsson L. Corticosteroids preoperatively diminishes damage to the C-fibers in microscopic lumbar disc surgery. Spine 2005; 30: 2362-7.

[57] Hayashi N, Weinstein JN, Meller ST, Lee HM, Spratt KF, Gebhart GF. The effect of epidural injection of betamethasone or bupivacaine in a rat model of lumbar radiculopathy. Spine 1998; 23: 877-85.

[58] Lee HM, Weinstein JN, Meller ST, Hayashi N, Spratt KF, Gebhart GF. The role of steroids and their effects on phospholipase A2: an animal model of radiculopathy. Spine 1998; 23: 1191-6.

[59] Minamide A, Tamaki T, Hashizume H, Yoshida M, Kawakami M, Hayashi N. Effects of steroids and lipopolysaccharide on spontaneous resorption of herniated intervertebral discs: an experience study in the rabbit. Spine 1998; 23: 870-6.

[60] Heyse-Moore GH. A rational approach to the use of epidural medication in the treatment of sciatic pain. Acta Orthop Scand 1978; 49: 366-70.

[61] Berman AT, Garbarino JL Jr, Fisher SM, Bosacco SJ. The effects of epidural injection of local anesthetics and corticosteroids in patients with lumbosciatic pain. Clin Orthop 1984; 188: 144-51.

[62] Rull BM, Miralles M, Aure S. Therapeutic epidural infiltrations in the lumbar nerve roots. Revista de Ortopedia y Traumatologia 1996; 40: 209-17.

[63] Bronfort G, Evans RL, Maiers M, Anderson AV. Spinal manipulation, epidural injections, and self-care for sciatica: a pilot study for a randomized clinical trial. J Manip Physiol Ther 2004; 278: 503-8.

[64] Hernandez R, Lopez F. Assessment of pain intensity in patients with diabetic polyneuropathy treated with peridural $2 \%$ lidocaine methylprednisolone acetate vs peridural $2 \%$ lidocaine. Anestesia en Mexico 1999; 11: 65-9.

[65] Kikuchi A, Kotani N, Sato T, Takamura K, Sakai I, Matsuki A Comparative therapeutic evaluation of intrathecal versus epidural methylprednisolone for long-term analgesia in patients with intractable postherpetic neuralgia. Reg Anesth Pain Med 1999; 24: 287-93.

[66] Helliwell M, Robertson JC, Ellia RM. Outpatient treatment of low back pain and sciatica by a single extradural corticosteroid injection. Br J Clin Pract 1985; 39: 228-31.

[67] White AH, Derby R, Wynne G. Epidural injections for the diagnosis and treatment of low-back pain. Spine 1980; 5: 78-86.

[68] Renfrew DL, Moore TE, Kathol MH, el-Khoury GY, Lemke JH, Walker CW. Correct placement of epidural steroid injections: Fluoroscopic guidance and contrast administration. AJNR Am J Neuroradiol 1991; 12: 1003-7. 
[69] Saberski LR, Kondamuri S, Osinubi OYO. Identification of the epidural space: is loss of resistance to air a safe technique? A review of the complications related to the use of air. Reg Anesth 1997; 22: 3-15.

[70] Botwin KP, Gruber RD, Bouchlas CG, et al. Complications of fluoroscopically guided caudal epidural injections. Arch Phys Med Rehabil 2001; 80: 416-24.

[71] Furman MB, Giovanniello MT, O'Brien EM. Incidence of intravascular penetration in transforaminal cervical epidural steroid injections. Spine 2003; 28: 21-5.
[72] Manchikanti L, Cash KA, Pampati V, Damron KS, McManus CD. Evaluation of lumbar transforaminal epidural injections with needle placement and contrast flow patterns: a prospective, descriptive report. Pain Physician 2004; 7: 217-24.

[73] Manchikanti L, Bakhit CE, Pampati V. The role of epidurography in caudal neuroplasty. Pain Digest 1998; 8: 277-281.

[74] Manchikanti L, Cash KA, Pampati V, Mc- Manus CD, Damron KS. Evaluation of fluoroscopically guided caudal epidural injections. Pain Physician 2004; 7: 81-92.

(c) Mohamed Mohi Eldin; Licensee Bentham Open.

This is an open access article licensed under the terms of the Creative Commons Attribution Non-Commercial License (http://creativecommons.org/licenses/by$\mathrm{nc} / 3.0 /)$, which permits unrestricted, non-commercial use, distribution and reproduction in any medium, provided the work is properly cited. 